renal failure. The hypertension which is an integral part of diabetic nephropathy causes hyalinization of the media of the arterioles, especially the afferent glomerular ones. Microangiopathy affecting the nutrient vessels to the nerve fibres produces irreversible neuropathy. Similar lesions have been demonstrated in the skin, ${ }^{5}$ and are a possible explanation for the high incidence of superficial infection.

Diabetics are very prone to atheroma of the large arteries. This develops early and is more advanced in extent than in non-diabetic subjects of the same age. ${ }^{6}$ The cause of this premature atheroma is unknown. Though even wellcontrolled patients have slightly raised levels of non-esterified fatty acids and triglycerides in the plasma, ${ }^{7}$ the increased incidence of atheroma is unlikely to be due to a disturbance in lipid metabolism. ${ }^{8}$ Perhaps microangiopathy of the vasa vasorum of the larger arteries is an important factor.

The relation between diabetes mellitus and peripheral vascular disease is complex. In one series it was noted that diabetics did not come to operation at a significantly earlier age than did non-diabetic patients with arterial disease, ${ }^{9}$ and it was doubted whether peripheral vascular disease was influenced by diabetes. ${ }^{1 ;}$ Most workers think, however, that diabetics are much more prone to ischaemic lesions of the lower limbs than are non-diabetic subjects. ${ }^{6}$ Atheroma of the large blood-vessels, neuropathy causing the patient to neglect minor traumatic lesions, and a generalized lowering of resistance to infection are all important predisposing factors. ${ }^{11}$ Nevertheless, gangrene sometimes occurs in limbs free of severe infection and with palpable arterial pulses at the knee and even at the ankle-joint. In their recent paper in the B.M.F. Drs. J. M. Moore and I. D. O. Frew ${ }^{12}$ described the results of an examination of the blood-vessels of the skin of the lower limb in 52 diabetics and 52 non-diabetic controls. They found microangiopathy in 46 of the diabetics and in only 3 of the controls. Furthermore, of 34 diabetics with lesions of the foot 21 did not have clinically severe atheroma of the large arteries, whereas microangiopathy was absent in only 4 of them. This emphasizes the importance of occlusive microangiopathy in the aetiology of the foot lesions seen in diabetes mellitus. ${ }^{13}$

Microangiopathy begins early in the course of diabetes mellitus. It occurs in the initial latent phase, ${ }^{7}$ when abnormalities in the glucose-tolerance test are provoked only by external stress or by special laboratory procedures. ${ }^{14}$ Though it progresses in intensity - and may be virtually universal in long-standing diabetes mellitus-it gives rise to clinical effects in only a minority of patients. It has been noted in diabetes secondary to pancreatic disease, and is probably the result of

${ }^{1}$ Ashton, N., Brit. med. F., 1957, 1, 1002.

Lancet, 1959, 2, 625

${ }^{3}$ Gellman, D. D., Pirani, C. L., Soothill, J. F., Muehrcke, R. C., and Kark, R. M., Medicine (Baltimore), 1959, 38, 321.

- Kimmelstiel, P., and Wilson, C., Amer. F. Path., 1936, 12, 83.

5 Handelsman, M. B., Morrione, T. G., and Ghitman, B., Arch. intern. Med., 1962, 110, 70 .

6 Bell, E.'T Diabetes Mellitus, 1960. Thomas, Springfield, Ill

' Forsham, P. H., and Grodsky, G. M., in Biochemical Disorders in Human Disease, p. 657, 2nd ed. Ed. by R. H. S. Thompson and E. J. King,
orsham, P. H., and Grodsky, G. M., in Biochemical Disorders in Human 1964. Churchill, London.

${ }^{-}$Allen, E. V., Barker, N. W., and Hines, E. A., Peripheral Vascular Diseases, 3rd ed., 1962. Saunders, Philadelphia.

- Martin, P., in Peripheral Vascular Disorders, ed. by P. Martin, R. B. Lynn, J. H. Dible, and I. Aird, 1956. Livingstone, Edinburgh.

10 Dible, J. H., Lancet, 1958, 1, 1031.

${ }^{11}$ Oakley, W., Catterall, R. C. F., and Martin, M. M., Brit. med. F., 1956, 2, 953 .

1: Moore, J. M., and Frew, I. D. O., ibid., 1965, 2, 19.

1.3 Goldenberg, S., Alex, M., Joshi, R. A., and Blumenthal, H. T., Diabetes, 1959, 8, 261.

${ }_{14}^{14}$ EutzGerald, M. G., and Keen, H., Brit. med. F., 1964, 1, 1568.

"Gilliland, I. C., Hanno, M. G., and Strudwick, J. I., Biochem. F., 1954, 56, XXXII. an abnormality in metabolism due to an inadequate amount of insulin. But it may progress even in well-controlled patients. Raised levels of serum glycoproteins have been noted in diabetics with vascular lesions, ${ }^{1516}$ and possibly microangiopathy is due to a seepage of polysaccharides from the circulation through foci of capillary damage. ${ }^{1}$ Nevertheless we still have much to learn about a very important aspect of diabetes mellitus.

\section{Treatment of Lung Cancer}

Resection is still the best treatment for bronchial carcinoma. Radiotherapy, although of great value for the relief of symptoms, cannot match the five-year cure rate of the surgeons, ${ }^{1}$ nor does it seem to have much to offer when used in combination with surgery ; indeed, it may have risks of its own. Chemotherapy with cytotoxic drugs such as nitrogen mustard, vinblastine, ${ }^{2}$ or other newer preparations is of little value whether they have been given on their own or in conjunction with surgery.

There is now fairly wide agreement that conservative resection in the form of lobectomy, where it is possible, offers as good a chance as the more radical pneumonectomy. The proportion of patients in whom it is done is probably more than a third of the total, and it has the advantage that the operative mortality is less than half that of pneumonectomy.

The incidence of bronchial carcinoma in Britain has risen inexorably year after year for over a decade, and 25,000 deaths were attributed to it in England and Wales in $1963{ }^{3}$ It is thus by far the commonest carcinoma affecting men, and accounts for $40 \%$ of the deaths of males from malignant disease. Even so on average any one general practitioner is likely to see only one patient with bronchial carcinoma each year. This emphasizes the great vigilance required to diagnose the condition early and thus to refer patients for treatment at a stage where there is some prospect of success.

It is difficult to find out what proportion of patients suffering from bronchial carcinoma are suitable for surgery, but probably only one-fifth of them fall into this group; in about three-quarters of these resection proves possible: The length of history of those who have been operated on does not appear to affect the results. ${ }^{4}$ However, if more patients have their disease recognized early enough to be found suitable for surgery, then a larger number will benefit from it.

Recent papers have shown that the five-year survival rate after resection for bronchial carcinomas is about $25 \%,,^{5-7}$ and in some series it has been notably higher than this. ${ }^{8}$ The figure compares favourably with the results of the surgical treatment of another common carcinoma-that of the stomach -in which few surgeons claim a five-year survival rate of more than $10 \%$. On the other hand the survival rates after surgery for carcinoma of the breast or the rectum are considerably better-in the region of $40 \%$. Despite a recent fall

Morrison, R., Deeley, T. J., and Cleland, W. P., Lancet, 1963, 1, 683. Crosbie, W. A., Kamdar, H., and Belcher, J. R., Brit. F. Dis. Chest, 1965, in press.

${ }^{3}$ The Registrar-General's Statistical Review of England and Wales for the Year 1963, Part I. H.M.S.O. 1965.

Rienhoff, W. F., Talbert, J. L., and Wood, S., Ann. Surg., 1965, 161, 674.

Belcher, J. R., and Anderson, R., Brit. med. F., 1965, 1, 948.

- Goldman, K.'P., Thorax, 1965, 20, 298.

Clagett, O. T., Allen, T. H., Payne.W. S., and Woolner, L. B., f. thorac. cardiovasc. Surg., 1964, 48, 391.

Flavell, G., Brit. med. f., 1962, 1, 284.

Capel, L. H., unpublished data. 
in the operative mortality the results in the survivors have improved little in the last fifteen years. ${ }^{5}$ Those patients who survive suffer less physical incapacity than might be expected. L. H. Capel ${ }^{9}$ has shown that a surprisingly high proportion not only return to work but actually go back to their old job. This is true both after lobectomy and after pneumonectomy, and there is little difference in this way between the two operations. When patients do eventually stop work they do so not because of the effects of the operation but because they have reached the age of retirement.

What does the future hold? It is unlikely that the fiveyear survival rate or the operative mortality being achieved by the present surgical methods will improve. Technical advances in radiotherapy may possibly lead to better results than surgery, but before this can be established the age-old difficulty must be overcome of selecting patients for a method of treatment whose results are unknown when a wellestablished method is available. Perhaps the cytotoxic drugs will eventually prove to be valuable, but none in use at present has been found to alter the prognosis significantly when given in doses small enough to avoid leucopenia. Topical application of them is being attempted for an increasing number of tumours, and some efforts have already been made to give them through the pulmonary arteries. Perhaps this is the field wherein the next advanoe lies.

\section{Noise and its Effects}

Noise and its possible effects on health are now subjects of acute public concern, as the number of conferences on the subject shows. F. I. Catlin ${ }^{1}$ has recently reviewed the topic, but, like other authorities, he concludes that the only damage which can definitely be confirmed is the effect on hearing. This can occur either from the traumatic effect of highenergy impulsive noise, such as gunfire, or from prolonged exposure to noise, and was noticed as long ago as 1886 when T. Barr ${ }^{2}$ described boilermakers' deafness. 'It is generally accepted that working conditions in which there is continual exposure throughout working hours to noise whose intensity exceeds $85 \mathrm{db}$. in any octave band in the speech-frequency range (250-4,000 c.p.s.) may cause permanent damage to hearing. ${ }^{3}$ Nowadays the need to protect workers in particularly noisy surroundings by the use of attenuators such as ear-muffs is accepted by the good employer. The Wilson Committee on Noise ${ }^{4}$ recommended that the Ministry of Labour should publicize the existing knowledge about the hazards of noise to hearing and should impress on industry the need to take suitable measures-including reducing noise at the source. It is possible that the hearing of the population as a whole has begun to be affected by the rise in ambient noise in cities through the growth of mechanization in transport, since traffic noise at the level of $90 \mathrm{db}$. is nowadays not infrequently encountered by the city dweller.

The results of the many investigations into the effects of noise on performance at work have been conflicting. At very

\footnotetext{
I Catlin, F. I., f. chron. Dis., 1965, 18, 509.

3 Barr, T., Proc. roy. phil. Soc. Glasgow, 1886, 17, 223.

Evidence by B.M.A. Committee to Committee on Noise, Brit. med. $\mathcal{F}$. Suppl., 1962, 1, 194.

Final Report of the Committee on the Problem of Noise, 1963, Command
Paper 2056, H.M.S.O. London

${ }^{5}$ Broadbent, D. E., Proc. roy. Soc. Med., 1957, 50, 225

and Little, E. A. J., Occup. Psychol., 1960, 34, 133

7 Rodger, T. F., Roy. Soc. Hlth $\mathcal{F}$, 1964, 84, 136.
}

high levels above $90 \mathrm{db}$. D. E. Broadbent ${ }^{5}$ and Broadbent and E. A. J. Little ${ }^{6}$ have shown that a worker engaged on a continuous task, such as watching a dial, will take longer to respond, and that momentary errors and aberrations will occur more readily. On the other hand, if people are short of sleep and are doing undemanding work of a routine nature, a rise in the level of noise will, through increased arousal, diminish the number of errors which are made.

Recent publications are, however, mainly concerned with the emotional effects of noise-with disturbance of communication and with annoyance. In the neighbourhood of London Airport conversation is impeded, teachers find difficulty in communicating with their pupils, and sermons are interrupted by the noise of passing aircraft. Annoyance, however, can occur when a person becomes aware of even a very slight noise, such as a dripping tap or when ice-cream chimes are sounded in a housing estate. It has been suggested that this kind of annoyance ${ }^{7}$ is due to the feeling that one's privacy is being interfered with and is akin to the reactions of an animal to an intrusion into its territory.

Annoyance, therefore, can bear little relation to the level of noise experienced, but it could be reduced by raising the standard of sound insulation in flats as a defence against the noise from neighbours and by better-designed windows to protect against traffic and aircraft noise.

Much noise is unnecessary and could be eliminated if more attention were paid to the noise factor in the design of vehicles and appliances. The Committee on Noise suggested imposing statutory noise limits or restrictions on use in the case of building construction and demolition plant, agricultural machinery, motor vehicles and motor-boats, lawnmowers, and power-saws. If people want to reduce noise they should, as consumers, insist on good sound insulation when having a house built, and when purchasing a domestic appliance such as a dish-washer or a vacuum cleaner they should pay attention to the noise it produces. While all this would certainly reduce noise and any effect it may have on mental health, the only hope of reducing much of the annoyance which we experience would be by paying more attention to good neighbourliness-turning down the noise of the loudspeaker, for instance, and avoiding slamming car doors in the middle of the night.

\section{Waiting in Out-patients}

Given the test words "out-patient department" in a freeassociation test, most laymen would undoubtedly reply, " waiting." This time-honoured connexion has existed since out-patient departments first opened their doors, as the picture on the cover of a new report ${ }^{1}$ on the subject shows. Nevertheless, in the last ten years or so several surveys have been made on waiting, and some progress has been made in reducing it-more, indeed, than is generally realized. Thus two Ministers of Health, Mr. Iain Macleod in $1954^{2}$ and Mr. Kenneth Robinson in $1965^{3}$ made similar statements on waiting in out-patient departments, both emphasizing that special attention should be paid to appointment systems, punctuality of staff, and reception of patients. As J. O. F. Davies points out in his preface to the report by the Nuffield Provincial Hospitals Trust, ${ }^{1}$ however, a rough comparison of the results in this survey with those in the earlier one ${ }^{4}$ showed that waiting times have been virtually halved in twelve years 